OLIVEIRA, Almir Leal de. O litoral do Nordeste do Brasil como objeto científico darwinista: as prospecções de John Casper Branner, 1899-1911. História, Ciências, Saúde - Manguinhos. Rio de Janeiro, v.21, n.3, jul.-set. 2014, p.931-949.

Resumo

\title{
O litoral do Nordeste do Brasil como objeto científico darwinista: as prospecções de John Casper Branner, 1899-1911
}

\section{The coast of Northeast Brazil as a Darwinian scientific object: the explorations of John Casper Branner, 1899-1911}

\author{
Almir Leal de Oliveira \\ Professor, Departamento de História/Universidade Federal do Ceará. \\ Avenida da Universidade, 2.762 \\ 60020-180 - Benfica - Fortaleza - CE - Brasil \\ almirleal@uol.com.br
} Aprovado para publicação em dezembro de 2013.

John Casper Branner, geólogo norteamericano, desenvolveu uma longa história de investigação no Brasil. Analisa-se, aqui, como ele tratou a geologia do litoral do Nordeste na Branner-Agassiz Expedition (1899) e na Stanford Expedition (1911). As expedições indicam como a geomorfologia das bacias sedimentares, dos recifes de arenito e dos recifes de corais foi caracterizada sob uma perspectiva evolutiva darwinista. Branner integrou o modelo de pesquisa de campo da história natural com as práticas da biologia moderna e da geologia dinâmica, e interpretou a evolução da formação geológica a partir dos fatores físico-químicos. Os estudos zoológicos identificaram o lugar da variação e das adaptações evolutivas das espécies marinhas isoladas como fator auxiliar da seleção natural.

Palavras-chave: John Casper Branner (1850-1922); Branner-Agassiz Expedition; Stanford Expedition; evolucionismo; darwinismo.

Abstract

John Casper Branner, a US geologist, had a long history of research in Brazil. The article analyzes his exploration of the geology of the coast of Northeast Brazil during the Branner-Agassiz (1899) and Stanford (1911) expeditions. In the findings from both voyages, Branner characterized the geomorphology of sedimentary basins, sandstone reefs, and coral reefs from a Darwinian evolutionary perspective, blending natural history's model of field research with the practices of modern biology and dynamic geology. He based his interpretation of the evolution of the geological formation on physical and chemical factors. Zoological studies identified the place of evolutionary variation and adaptations of isolated marine species as an auxiliary factor in natural selection.

Keywords: John Casper Branner (1850-

1922); Branner-Agassiz Expedition; Stanford Expedition; evolutionism; Darwinism. 
$\mathrm{E}$ ste artigo procura situar as principais contribuições científicas de John Casper Branner (1850-1922) na sua interpretação das dinâmicas evolutivas do litoral brasileiro, focando as polêmicas teóricas, a colaboração científica e os desafios metodológicos que enfrentou em sua trajetória de pesquisa. Ele prospectou o litoral entre a Bahia e o Rio Grande do Norte, em 1899 (Branner-Agassiz Expedition), e, em 1911, organizou outra viagem de campo (Stanford Expedition) para investigar o litoral entre a foz do rio Amazonas e o Rio Grande do Norte. O corolário dessas expedições foi analisado por diferentes centros de investigação norte-americanos. No seu conjunto, os resultados das interpretações geológicas e as coleções biológicas produzidas por essas expedições são indicações dos problemas evolutivos trabalhados no período e constituem importante fonte de estudo sobre como o litoral brasileiro foi inserido no debate evolucionista norte-americano.

John Casper Branner teve uma longa relação de investigação científica no Brasil. Visitou o país a primeira vez em 1876 e a última em 1917. Foram mais de quarenta anos de estudos, de colaboração científica, troca de correspondência e de materiais biológicos, entre várias outras atividades de intercâmbio, marcados por tentativas de interpretação evolutiva da natureza dos trópicos, dos seus agentes dinâmicos e da sua particular e exuberante aparência. Durante esse período, Branner foi um dedicado acadêmico que procurou, com base no objeto geológico, formar uma interpretação sistemática da evolução geológica brasileira a partir de um espírito científico colaborativo, de treinamento em problemáticas teóricas e, sobretudo, no desenvolvimento de uma metodologia científica que tivesse o território tropical como objeto de reflexão.

\section{Entre duas tradições}

Do ponto de vista das orientações teóricas de Branner, devemos ter em mente que o período entre o final do século XIX e o início do século XX foi marcado por um debate de amplas proporções sobre a validade da teoria da seleção natural proposta por Charles Darwin (18091882). Situado entre duas marcantes tradições científicas, a metodologia científica de John Casper Branner não se encontra aparentemente definida em nenhum de seus escritos. Ele não era um teórico dos estudos geológicos e tampouco estava preocupado em definir a priori uma teoria e buscar os elementos empíricos de sua comprovação. Sua produção foi investigativa, suportando o ambiente de problematizações teóricas e da validação das interpretações sob rigorosa análise de evidências. Em meio às crises de paradigmas, criou instrumentos de análise, assimilou novos procedimentos e elaborou alternativas analíticas (Kuhn, 2011, p.107 e s.).

Ao longo de sua formação científica e carreira acadêmica, Branner experimentou duas grandes controvérsias, que utilizamos para situar sua agenda de pesquisa. A primeira foi a gradual aceitação da teoria transformacionista darwinista. A segunda foi o questionamento da teoria da evolução pelas alternativas teóricas da mutação, período denominado por Julian Huxley como o "eclipse do darwinismo" (Bowler, 1983, p.246). O conteúdo dessas polêmicas delineou seus estudos da natureza do litoral brasileiro.

A dificuldade de aceitar os princípios darwinistas provinha da sua formação em história natural em Cornell (onde ingressou em 1869), marcada por um rigoroso treinamento da observação da natureza pelos modelos classificatórios de Louis Agassiz (1807-1873). Nesse 
período, Branner foi aluno e assistente de Charles Frederick Hartt (1840-1878). Chegou a ter aulas com Agassiz, assim como seus colegas David Starr Jordan (1851-1931), Orville Derby (1851-1915), Richard Rathbun (1852-1918), entre outros. A convicção de Agassiz sobre o método científico, baseado na cuidadosa observação da natureza como único instrumento que poderia levar a uma séria interpretação do mundo natural, fazia dele um professor implacável no que se refere à produção das evidências empíricas como testemunhos imprescindíveis para a interpretação do mundo natural. Segundo Roberts (2009, p.81), a forma como Agassiz treinava seus alunos exigia uma grande dedicação ao trabalho empírico. Jordan (1922) relatou em suas memórias a forma como foi iniciado na descrição e na análise morfológicas por Hartt, analisando e classificando moluscos (Brachiopods) que ele trouxera do Brasil em 1870. Ainda segundo Roberts, o exame das evidências a partir da observação da natureza era determinante para aceitação ou rejeição de uma abordagem teórica. Sem base empírica convincente, não era possível aceitar as proposições de Darwin. Branner herdou essa "inflexível insistência" da sustentação das explicações geológicas amparadas em uma avaliação muito cuidadosa das evidências coletadas em pesquisa de campo (Roberts, 2009, p.96).

Na década de 1870, a maioria dos naturalistas debatia a aceitação da teoria da evolução por seleção natural em substituição à ideia das sucessivas criações em distintas províncias zoológicas (Bowler, 1983, p.189; Mayr, 1982, p.501 e s.). Hartt estava em meio a esse debate. Havia publicado em 1870 o relato de suas viagens de campo pelo Brasil. Suas conclusões acerca da geologia na América estavam no foco do debate científico norte-americano. No mesmo ano da publicação de Geologia e geografia do Brasil (1870), Alfred Russell Wallace (1823-1913) escreveu um artigo na Nature no qual fez duras críticas ao livro de Hartt, como a ausência da comprovação das teorias da glaciação na bacia do Amazonas, a ausência de um mapa geológico geral, o limitado nível de informações do interior do Brasil etc. Entretanto, Wallace admitia que Hartt estava passando por um momento de redefinição de sua concepção, herdada de Agassiz, sobre a glaciação do Brasil. No Brasil, Guilherme Schüch, barão de Capanema (18241908), também discordava da ideia da glaciação (Souza, 2009, p.105).

Hartt tinha dúvidas das explicações de Agassiz sobre a glaciação dos trópicos, ensaiando uma interpretação geológica que considerava a ação dos elementos erosivos nos trópicos, mas continuava admitindo a glaciação como teoria mais convincente. Ele dizia que, após visitar a região do maciço da Tijuca, no Rio de Janeiro, em busca das marcas da glaciação, convenceuse de que os granitos ali encontrados estavam fortemente decompostos pela ação do clima tropical e da vegetação. Dizia Hartt (1870, p.29): “Eu desejo registrar aqui que comecei meus estudos com a convicção de que o professor Agassiz estava errado e fiquei satisfeito que minhas observações independentes confirmaram os resultados da sua autoria".

A aceitação de uma indicação metodológica de Darwin (agentes erosivos nos trópicos), ou mesmo de incorporá-la como atividade de pesquisa, não significava propriamente a incorporação de toda uma explicação evolutiva geral da geologia do Brasil. Darwin sugeriu que a formação granítica das serras do litoral brasileiro teria adquirido tal aspecto a partir do lento recuo do oceano, associado com o extraordinário trabalho erosivo nos trópicos. Hartt não incorporou nas suas explicações o lento recuo do oceano como uma variável aceitável de interpretação. Digamos que, por esse período (1870), quando Hartt treinava seus alunos em Cornell, ele reavaliava suas posições teóricas. Brice e Figueirôa (2001) sustentam que 
Hartt estaria "firmemente convencido" de que a teoria de Agassiz sobre a glaciação dos trópicos estava errada, porém as suas relações acadêmicas e profissionais com Agassiz o faziam ser muito seleto com o que publicava sobre o tema. Se não totalmente convencido, Hartt ia direcionando seu olhar para a especificidade dos agentes erosivos nos trópicos, tema que certamente influenciou a agenda científica de seus alunos. Este foi o primeiro debate científico delineador da agenda de investigação de John Casper Branner no Brasil: a busca por evidências da evolução.

No período entre o seu ingresso em Cornell (1869) e a sua primeira viagem ao Brasil (1874), acompanhando Charles Frederick Hartt, Branner acumulou, portanto, uma formação em metodologia científica que definia o lugar da observação da natureza como componente principal do acúmulo de evidências empíricas para aceitação/rejeição de problemas teóricos. Os temas da erosão e dos agentes dinâmicos da geologia, derivados das teorias da glaciação dos trópicos (agentes erosivos nos trópicos), seria parte das suas preocupações científicas.

Entre a sua formação como geólogo de campo e a definição de uma agenda de pesquisa com objeto teórico evolutivo propriamente, em especial sobre o litoral brasileiro, Branner teve uma formação acadêmica e profissional característica do campo da geologia no período. Devemos ter em mente que as ciências geológicas no século XIX estavam tomadas pelo debate entre correntes conflituosas e de afirmação de um conhecimento pragmático. Ligada a uma herança descritiva das ciências naturais, a busca de evidências que explicassem as transformações da superfície da Terra em suas variadas formas estava associada a uma renovação constante de problemáticas, de descobertas e de mapeamento frequente das ocorrências dos fenômenos naturais. Somente a partir de um conhecimento sistematizado com base nas observações e informações coletadas, tratadas em esboços, mapas, tabelas, gráficos, uma vez processadas as informações, é que as publicações dos resultados se realizavam. Por outro lado, as atividades profissionais do geólogo de campo eram variadas e geralmente marcadas pelas aplicações que poderiam oferecer aos processos industriais e comerciais (Greene, 1982; Klaver, 1997).

Podemos ver isso na trajetória profissional de Branner no Brasil. Ainda em 1876 ele trabalhou como assistente de engenheiro e explorador de minas de ouro em Minas Gerais, familiarizando-se com a coleta de dados e a identificação dos terrenos do Paleozoico. Após um curto período nos EUA, retornou ao país contratado pela empresa de Thomas A. Edison (1847-1931) para pesquisar fibras vegetais que pudessem ser usadas em lâmpadas incandescentes. Nessa época, viajou pela Amazônia, pela Argentina, pelo Uruguai e pelo Paraguai, retornando aos EUA em 1881. No ano seguinte, foi contratado pelo Departamento de Agricultura norte-americano para estudar insetos que atacavam as plantações de algodão e cana-de-açúcar, quando viajou pelos estados do Norte e Nordeste do país, fazendo suas observações entomológicas. Em 1883, Branner retornou aos EUA, onde iniciou uma série de publicações sobre sua experiência de campo no Brasil. Essa trajetória de consolidação da carreira de geólogo, participando em trabalhos de campo orientados por problemáticas científicas ou tecnológicas, lastreada pelo rigor científico e geralmente desenvolvida em trabalho colaborativo, foi uma das marcas nas carreiras dos ex-alunos de Hartt nos EUA e no Brasil, o que deixou uma profunda contribuição ao desenvolvimento das ciências geológicas, das engenharias e das ciências naturais. No Brasil, Orville Derby foi uma "influência decisiva" 
na formação de engenheiros como Theodoro Sampaio (1855-1937), Miguel de Arrojado Ribeiro Lisboa (1872-1932) e muitos outros. Santos (2010, p.319-321) destacou que tal formação científica e profissional, além de desenvolver uma "abordagem integrada dos fenômenos físicos", capacitou esses profissionais a lidar de forma pragmática com a pesquisa científica e com a estrutura administrativa do poder público.

Branner percorreu um longo caminho de investigação empírica e de formação profissional para chegar a conclusões evolutivas da geologia dos trópicos, atingindo, em 1896, um viés interpretativo preocupado, concomitantemente, com as causas geológicas e as suas consequências para o desenvolvimento da vida. ${ }^{1}$ No Brasil, a publicação de "A Suposta glaciação do Brasil", na Revista Brasileira, parecia finalmente abrir uma nova perspectiva de trabalho investigativo sobre o Brasil, onde o litoral seria uma preocupação constante de associação entre formação geológica e evolução da vida nos trópicos.

Até aqui tenho me limitado à exposição dos fatos que se relacionam diretamente com a glaciação. Além desses fatos, é assunto da maior importância a continuidade da vida desde a idade terciária até o presente, especialmente nas partes tropicais e subtropicais. Se a glaciação tivesse sido cósmica, como Agassiz sugeriu - se ela tivesse tido lugar no próprio Equador - então os raciocínios biológicos concernentes à origem e distribuição da vida atual do globo estariam totalmente errados (Branner, 1896, p.111).

Esse era o claro posicionamento de Branner junto ao público brasileiro em 1896, quando, após mais de vinte anos de pesquisa de campo, chegou à conclusão de que a geologia brasileira deveria ser tratada como um objeto científico darwinista, a partir de uma compreensão das dinâmicas relações entre mudanças geológicas e evolução da vida. Não é fácil medir as palavras desse autor em, 1896, colocando-se, depois de um longo período de observação, maturação e interpretação da geologia brasileira, no centro do debate darwinista da época.

Se a problemática da aceitação da teoria da seleção natural e transmutação das espécies foi o contexto teórico da formação e profissionalização de John Casper Branner e seu grupo de amigos que se formaram em Cornell College, na década de 1870, sob a supervisão e o treinamento de Frederick Hartt, a profissionalização e a vida acadêmica dos egressos de Cornell foram marcadas por outro grande debate teórico sobre a validação da teoria da hereditariedade: os questionamentos ao darwinismo por teorias alternativas à seleção natural.

A segunda grande problemática teórica que marcaria a produção científica de Branner e seus colaboradores no Brasil seria, a partir da década de 1890, mas principalmente a partir de 1900, a crítica ao evolucionismo darwinista pelos adeptos da teoria da mutação. O debate evolucionista foi intenso nos periódicos científicos norte-americanos no final do século XIX e início do século XX. Muito mais que um debate metodológico entre grupos distintos de zoólogos e geólogos, a questão central se firmava na validação das evidências empíricas da seleção natural, no motor evolutivo das espécies e no tempo necessário para que a evolução pudesse ocorrer. Julian Huxley (1887-1975) descreveu esse momento como o "eclipse do darwinismo" (Bowler, 1983). As principais críticas recaíam sobre a ausência das comprovações físico-químicas da hereditariedade. Assim, os críticos da seleção natural exploravam os limites empíricos da teoria da seleção natural e elaboraram interpretações alternativas ao entendimento da evolução guiada pelo acaso e pelas tentativas e erros da 
natureza. Bowler (1983, p.257-281) distingue as três principais correntes críticas da teoria da evolução por seleção natural: neolamarckistas (caracteres fenótipos adquiridos por herança), defensores da ortogênese (evolução por forças internas próprias dos organismos) e os mendelianos (ou adeptos da teoria da mutação).

Os historiadores da biologia (Allen, 1975; Mayr, 1982; Coleman, 1985) ainda ressaltam que esse período foi marcado por uma oposição entre naturalistas evolucionistas e emergentes modernos biólogos, ou entre morfologia e fisiologia. O panorama que traçam dos naturalistas evolucionistas na virada do século XIX para o seguinte é o de um conhecimento descritivo, morfológico, ligado ao trabalho de campo com preocupações meramente quantitativas na descrição das variações da vida e de sua distribuição geográfica. Por outro lado, a biologia moderna emergia com base em métodos experimentais, em estudos fisiológicos, principalmente ligados aos parâmetros físico-químicos da construção dos dados empíricos. Allen (1978, p.41 e s.) caracteriza as contestações ao darwinismo como uma revolta de fisiologistas contra morfologistas, principalmente a partir do entendimento dos mecanismos da hereditariedade, que não poderiam ser explicados de forma mecânica. Vários historiadores criticaram essa dicotomia entre morfologia e fisiologia, ou entre uma antiga história natural descritiva/ morfológica e uma fisiologia comprometida com métodos modernos e experimentais (Magnus, 1993; Largent, 2009). O importante aqui é ressaltar que o debate evolucionista foi intenso no final do século XIX e início do século XX, que as temáticas levantadas pelas teorias alternativas da evolução por seleção natural estavam presentes nas preocupações científicas dos pesquisadores da Universidade de Stanford e que essas questões foram fundamentais na definição das prospecções que John Casper Branner realizou no litoral brasileiro.

Momento definido como um dos mais críticos para a teoria da evolução por seleção natural, em especial a partir da difusão das alternativas teóricas da mutação, as investigações desenvolvidas coletivamente na Universidade de Stanford buscavam comprovar de modo empírico os pontos desenvolvidos por Charles Darwin, principalmente no que se refere às leis de distribuição das espécies, à biogeografia da vida marinha e ao papel do isolamento sobre a divergência das espécies separadas por barreiras naturais. Uma compreensão histórica das investigações e prospecções darwinistas realizadas nesse período no litoral brasileiro, mas também em outras biogeografias, e de como o debate evolutivo está situado para esses cientistas, requer um olhar cuidadoso do quadro teórico no qual eles se encontravam situados. ${ }^{2}$

Por volta de 1900, estava constituído em Stanford um grupo de naturalistas que desenvolviam um trabalho colaborativo e interdisciplinar de investigação zoológica caracterizado pela defesa do darwinismo, pela pesquisa de campo, pela divisão dos trabalhos acadêmicos (de campo, laboratorial e de treinamento) e pela perspectiva de trabalho conjunto com outros pesquisadores e instituições. Faziam parte desse grupo, além de Branner, que em 1898 passou a ocupar a vice-presidência da universidade, e Jordan, Vernon Lyman Kellogg (1867-1937), professor de entomologia, Charles Henry Gilbert (1859-1928), ictiologista, e Harold Heath (1868-1951), professor de embriologia, entre outros.

Essa perspectiva de trabalho parece ter sido adotada por David Starr Jordan, presidente da universidade, fundamentado no que ele chamou de "colaboração solidária" (sympathetic cooperation): um espírito colaborativo entre estudantes e professores como ingrediente de 
uma formação profissional de aperfeiçoamento científico e técnico. Jordan afirma em suas memórias que esse espírito colaborativo foi trazido de sua experiência na então recémcriada Cornell. Segundo ele: "Os três anos e meio que eu passei em Cornell exerceram uma influência controladora sobre minha carreira subsequente" (Jordan, 1922, p.95). Magnus (1993, p.55-63) também destaca o estilo de investigação de grupo implementada por Jordan em Stanford. Liderando um grupo de variadas qualificações, eles desenvolveram trabalhos zoológicos não apenas com objetivos quantitativos, morfológicos, estatísticos, mas também experimentais, laboratoriais, fisiológicos, incorporando contribuições de áreas como a geologia e a paleontologia. Wourms (2007, p.231 e s.) destaca que Jordan criou um forte departamento de zoologia, bem como um museu de história natural e um laboratório de biologia marinha - a Hopkins Marine Station, fundada em 1892 em Pacific Groove, Califórina, primeiro laboratório marinho da costa Oeste norte-americana. Ele também destaca que, além da pesquisa colaborativa interna, os professores desenvolviam uma determinada divisão institucional do trabalho de pesquisa em que os trabalhos de sistemática e estudos morfológicos eram levados a cabo, principalmente, pelo museu e pelos laboratórios, e as equipes de pesquisadores podiam se dedicar ao trabalho experimental. De fato, tanto Branner quanto Jordan não só estavam envolvidos com a classificação e conservação dos materiais biológicos como também organizaram e participaram de trabalhos de campo. Entre 1900 e 1911 foram realizadas diversas expedições em diferentes locais, como Japão, Havaí, Samoa, México, Canadá e Brasil, assim como desenvolvidas pesquisas de campo ao longo da costa norte-americana do Pacífico.

\section{Investigações evolutivas darwinistas}

Quando John Casper Branner realizou suas prospecções evolutivas no litoral do Brasil, os naturalistas de Stanford estavam mobilizados contra os ataques dos mutacionistas à teoria da seleção natural. ${ }^{3}$ Talvez o melhor exemplo para evidenciar a preocupação científica e o caráter teórico da reflexão evolutiva desse grupo de naturalistas no período seja o livro de Vernon Lyman Kellogg Darwinism To-day, publicado em 1907, para criticar as alternativas à teoria da evolução de Darwin. Segundo Gould (2002, p.353), Kellogg, "o autor do mais fino livro sobre as variedades das teorias evolutivas e as suas distinções", distinguiu, coerentemente, o que seria alternativa à seleção natural (neolamarckismo e ortogêneses) do que seria auxiliar à seleção natural (saltacionismo, mendelismo, mutacionismo). ${ }^{4}$ Com a distinção entre mecanismos auxiliares e mecanismos alternativos à seleção natural, Kellogg focou o particular interesse que havia no processo de transmissão de caracteres adquiridos por adaptação das espécies ao ambiente natural. Se caracteres adquiridos por adaptação constituíssem um processo raro e incomum, limitado a específicas condições do grupo (isolamento, por exemplo), essa força adaptativa não concorreria propriamente com a seleção natural (sobrevivência dos grupos mais bem adaptados); porém, se essa força natural fosse constante e ocorresse com relativa frequência, aí, sim, ela seria uma concorrente da seleção natural. Para os neolamarckistas, a herança dos caracteres adquiridos se dava de geração a geração, e, assim, para Kellogg, essa era uma teoria alternativa ao que Darwin teria proposto. No caso da ortogênese, uma força interna dos organismos que determinaria as linhagens mais bem adaptadas também seria 
considerada uma teoria alternativa, uma vez que essa força tornaria sem consequências a seleção natural. Mas como defensores do darwinismo, o problema das mutações ainda deveria ser enfrentado de maneira mais empírica; afinal, a adaptação por grandes saltos concorreria ou não com o processo de seleção natural? Ou seria uma força auxiliar nesse processo natural? Nesse caso, o trabalho de August Weismann (1834-1914) sobre a hierarquia consistiria numa teoria auxiliar, e não concorrente, da seleção natural.

Outra indicação teórica, com implicações metodológicas, que nos ajuda a entender o trabalho de prospecção evolutiva do litoral do Brasil feita por Branner é o artigo de David Starr Jordan, publicado em 1905, para enfatizar o lugar do isolamento como um fator de especiação e divergência de caracteres em evolução (Jordan, 1905). De acordo com Magnus (1993, p.65 e s.), o artigo de Jordan procurava destacar o lugar das barreiras naturais e do isolamento na distribuição das espécies. Jordan reconhecia que o isolamento era um fator de precondição - mas não a causa - da seleção natural. Assim, o isolamento não concorreria, e sim contribuiria, com o processo de especiação. A ideia de como o isolamento de um mesmo grupo zoológico favorecia a especiação, questão que mobilizou Jordan e seu grupo, era prospectada e documentada nos trabalhos de campo, visando registrar a distribuição das espécies, a adaptação às variações ambientais, a adaptação às barreiras físicas para, finalmente, detectar as especiações em condições de isolamento por barreiras naturais. Jordan, nesse período um ictiologista nacionalmente reconhecido, falava que os caracteres adaptativos não dependiam propriamente do isolamento, mas da seleção natural; porém, nos caracteres não adaptativos - aqueles que distinguem um grupo como subespécie, e, portanto, a origem de uma filogenia específica - a força do isolamento era notável. Identificar uma biogeografia passível de ser prospectada com essa problemática (barreiras naturais, populações isoladas), documentar sua zoologia, identificar o tempo geológico, realizar estudos fósseis e classificar subespécies e novas espécies constituíam uma perspectiva de metodologia científica para evidenciar a força do isolamento nos processos evolutivos.

Kellogg também explorou o tema do isolamento e a forma como este era tratado por cientistas naturais. Para ele, alguns biólogos, "homens de laboratório" (morfologistas, citologistas), geralmente não consideravam o isolamento uma influência efetiva no processo de formação de distintas espécies, mas, por outro lado, os homens de campo, os "chamados naturalistas" (taxonomistas e estudiosos da distribuição das espécies), encontravam uma efetiva força do isolamento nos processos de seleção natural (Kellogg, 1907, p.232). É importante salientar que, na visão de Jordan e Kellogg, o isolamento, em si, não seria totalmente suficiente para gerar uma nova espécie. A segregação das espécies por barreiras naturais (geográficas, topográficas) ou fisiológica e sexual não concorreriam com a seleção natural. Uma variação congênita de um grupo de espécies poderia ocorrer e se perder no interior de um grupo, caso essa variação não fosse predominante, mas a variação em grupos isolados poderia desencadear o processo de formação de uma nova espécie: "Na verdade, em minha opinião, a prova dos efeitos do isolamento (meios ou modos de isolamento) no estabelecimento das espécies é algo muito necessário para o suporte geral da teoria da seleção natural. Seleção natural precisa da ajuda do isolamento ... As provas disso me parecem óbvias" (Kellogg, 1907, p.233). 


\section{Branner-Agassiz Expedition, 1899}

Professor de geologia em Stanford desde 1891, e participando da implantação da universidade juntamente com David Starr Jordan e Vernon Lyman Kellogg, John Casper Branner organizou uma viagem de investigação ao Brasil em 1899. A partir dessa expedição, Branner revela-se como cientista maduro, aprofundando seu conhecimento de geólogo de campo, mas, sobretudo, prospectando uma área com interesse em documentar uma biogeografia específica. A expedição foi financiada pelo amigo Alexander Agassiz, ${ }^{5}$ também preocupado com as biogeografias das ilhas tropicais e a formação das ilhas vulcânicas, atóis e corais. Branner percorreu durante os meses de junho e agosto o litoral entre o Rio Grande do Norte e a Bahia. Visitou pequenas vilas e estuários ao longo da costa. Coletou fósseis e peixes. Fotografou a formação de recifes de arenito e desenhou mapas topográficos. Após seu retorno aos EUA, iniciou a publicação de uma série estratégica de artigos para explicar a formação geológica dos recifes de arenito e recifes de corais do Nordeste do Brasil. Essa série de artigos culminou com a publicação, em 1904, da monografia The stone reefs of Brazil, pelo Museu de Zoologia Comparada de Harvard.

A sua primeira publicação foi na revista The American Geologist, em dezembro de 1899. Era um artigo curto, de descrição morfológica dos recifes de arenito da região de Natal, Rio Grande do Norte. A estratégia de Branner no artigo era a divulgação das características geomorfológicas particulares dessa parte do litoral do Brasil. Ele privilegiou a descrição dos aspectos físicos desse litoral, não se preocupando com os problemas da origem geológica ou a história natural dos recifes, o que faria em outro artigo. Enfatizou a descrição geomorfológica (relevo, estrutura, topografia, agentes erosivos, vegetação etc.) em forma de notas de campo e deixou para mais tarde as explicações evolutivas.

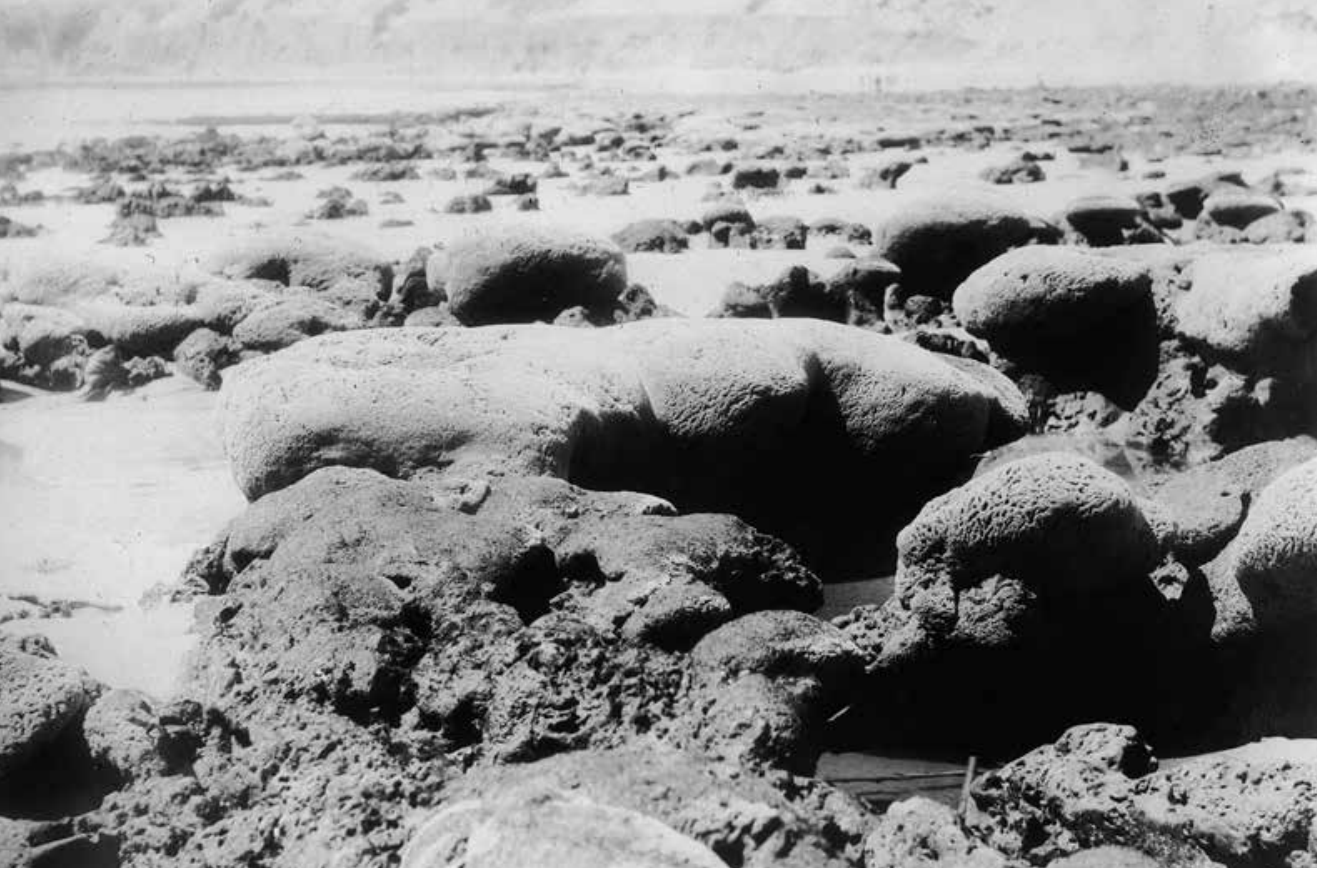

Figura1: Bahia Formosa, recifes de arenito (Branner-Agassiz expedition to Brazil, 1899; cortesia de Department of Special Collections/ Stanford University Libraries) 
Branner ressaltava nesse artigo as características gerais de aparência física dos recifes nos arredores da cidade de Natal, destacando sua curiosa aparência. Segundo ele, qualquer pessoa mal informada teria dificuldade de acreditar que essa formação costeira não era um trabalho artificial. "Qualquer pessoa acostumada com os recifes do Brasil, vendo o do Rio Grande do Norte, dificilmente acreditaria que não se trata de uma obra de arte" (Branner, dez. 1899, p.342.). As notas de campo, publicadas em coautoria com Charles Edward Gilman, aluno de geologia em Stanford e que o acompanhou na viagem ao Brasil, buscavam uma precisão dos dados que pudessem particularizar a formação costeira. Branner buscava as evidências empíricas que servissem de elementos analíticos para a geofísica que queria construir. Assim, largura, comprimento, aparência, posição astronômica, direção, constituição mineral das rochas, estratigrafia, geografia, vegetação associada, variação das marés etc. eram documentados como instrumentos de análise. A associação da formação dos recifes com as diferentes condições físicas e atmosféricas indicava um trabalho de campo preocupado com os aspectos dinâmicos do ambiente ao longo do tempo. Branner procurava registrar essas marcas. Dessa forma, a aparência dos recifes era associada aos acidentes geográficos (rios, canais, correntes, vento, marés) e descrita como parte integrante da paisagem de dunas, estuários, mangues, lagoas, restingas etc. As descrições zoológicas dos recifes (peixes, moluscos e crustáceos), botânicas (algas e vegetação), dados paleontológicos (fósseis de moluscos), assim como os dados mineralógicos, foram cuidadosamente recolhidos, anotados e descritos no artigo.

Em agosto de 1900, foram publicados mais quatro artigos científicos comunicando os resultados da Branner-Agassiz Expedition. ${ }^{6} \mathrm{O}$ artigo de Branner sobre a geologia do litoral se dedicava ao tema das barreiras costeiras: a bacia sedimentar do Mucuri, na Bahia, e a bacia sedimentar de Alagoas. Segundo ele, a origem geológica das seções remetia ao Mesozoico, e ambas as seções poderiam ser caracterizadas por camadas de sedimentos sobre as rochas cristalinas. A indicação da idade geológica da formação de barreiras dessas partes do litoral, com a sua fragmentada estrutura e a dispersão dos sedimentos, evidenciava que Branner estava atento à evolução das margens continentais e ao movimento das tectônicas, princípios discutidos no período (Oreskes, 1999), e que, a partir de 1906, depois do terremoto de San Francisco, será tema particularmente explorado por Branner, Grove Karl Gilbert (1843-1918) e outros. Branner publicou as primeiras estratigrafias dessas áreas, realizou análises mineralógicas, paleontológicas e, sobretudo, esforçou-se para detalhar precisamente as características dos aspectos geomorfológicos. Por outro lado, seus estudos dos sedimentos dessas bacias nos indicam a forma como ele observou a ação contínua dos elementos dinâmicos do clima, a variação do nível do oceano ao longo do tempo geológico e as forças químicas atuantes na compactação dos sedimentos.

Em 1904, John Branner publicou extensa monografia sobre a geologia dos recifes brasileiros. O estudo foi o resultado de profundo contato com a temática da geologia do litoral, mas, especialmente, um dos resultados da expedição de 1899. A monografia, com mais de trezentas páginas, contendo mapas, fotografias, gráficos e plantas, foi publicada pelo Museu de Zoologia Comparada de Harvard (Branner, maio 1904). Esse estudo foi um importante marco para a distinção entre os recifes de arenito e as formações de recifes de corais no Brasil. No final de 1904, Branner elaborou um resumo de suas investigações, que foi lido na Geological Society of America, em 28 de dezembro, e publicado no seu Bulletin, no ano seguinte. Finalizando o 
estratégico plano de publicações, ele resumiu sua teoria para a formação dos recifes do litoral do Brasil demonstrando seu fascínio por este ambiente natural:

Os recifes do Brasil são diferentes da maioria dos recifes do mundo. ... Essas pedras de recifes são únicas, ou quase um particular fenômeno geológico. Darwin, que viu esses recifes em Pernambuco, duvidava 'se no mundo inteiro haveria outra estrutura natural que tivesse tão artificial aparência'. A maravilha dessas estruturas é incrementada quando elas se encontram numa costa por mais de 1.600 quilômetros (Branner, jan. 1905, p.1-2).

A explicação geológica que emerge desse estudo de Branner sobre a origem dos recifes era, sobretudo, uma análise dinâmica dos eventos geológicos. Para explicar a particular formação dos recifes brasileiros, baseou-se nos processos erosivos das áreas tropicais, a ação das chuvas, da rápida decomposição das rochas e dos processos químicos envolvidos nessa dinâmica. Sua explicação a respeito da formação dos recifes e da dificuldade de distinguir os recifes de arenitos dos recifes de corais baseava-se, assim, em uma perspectiva dinâmica dos estudos geológicos.

Muito mais que uma simples estratigrafia, Branner, inclusive com as análises paleontológicas, associou a formação de arenito a formações que tiveram sua origem no Cretáceo (e estrato de base dos recifes) posteriormente cobertas por rochas sedimentares do período Terciário (Eoceno) e sobrepostas por sedimentos compactados pela depressão dos oceanos (Plioceno). O processo teria sido favorecido e alterado pelas mudanças climáticas e geográficas durante esse longo período. Os processos físicos e químicos explicariam a atual

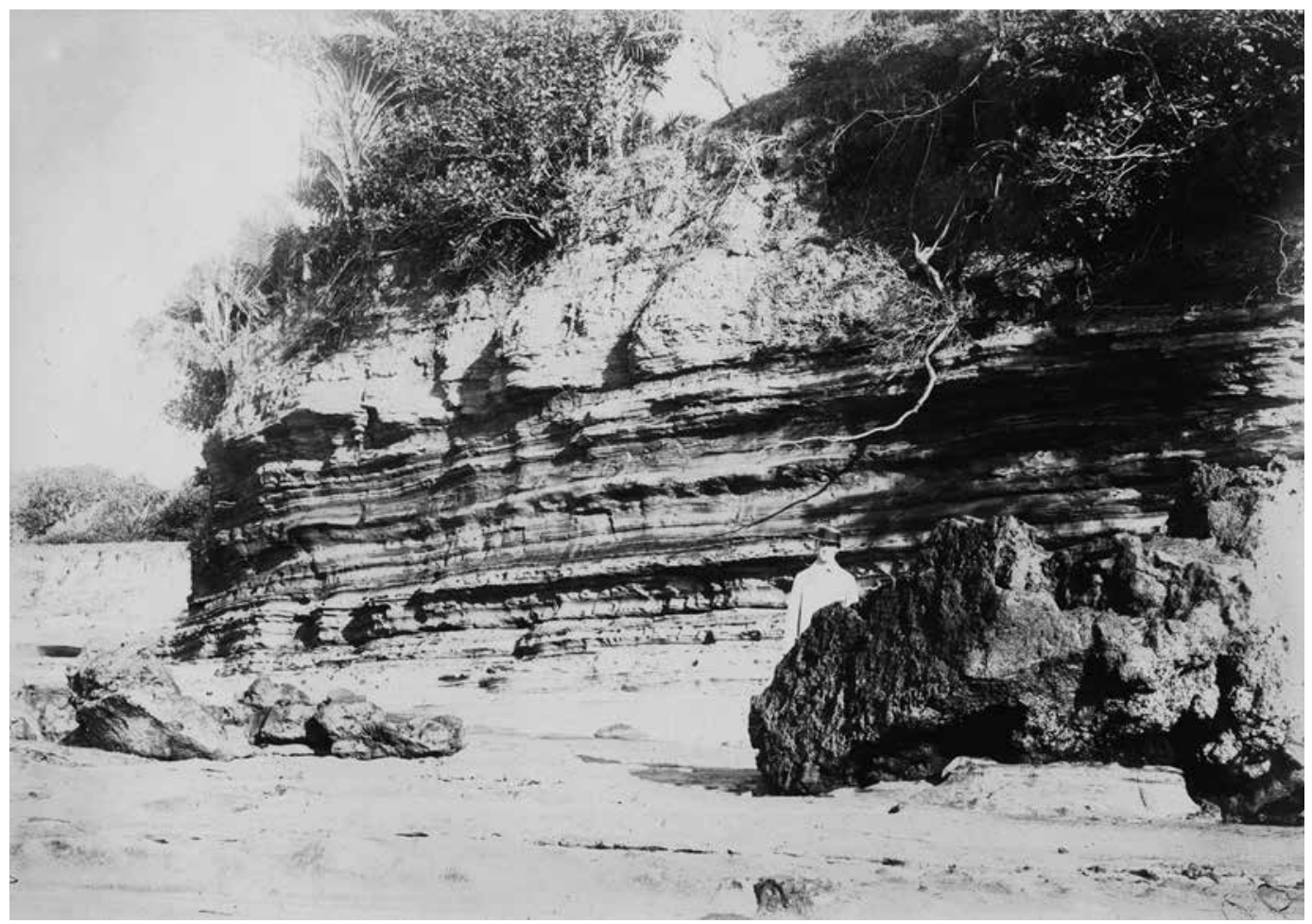

Figura 2: Barreira de Camaragibe, formação Cretáceo (Branner-Agassiz expedition to Brazil, 1899; cortesia de Department of Special Collections/Stanford University Libraries) 
aparência particular dos recifes, principalmente dos que se localizam próximo às fozes dos rios da região. Segundo ele, os distúrbios da geografia do litoral causados pelo depósito de sedimentos oriundos dos manguezais, pela ação das correntes marinhas e pelo contato com a água doce dos rios geraram ambientes propícios ao crescimento, sobre essas camadas, dos recifes de corais.

Branner resumiu, desta forma, a história geológica e geográfica da formação do litoral:

A maior parte das rochas costeiras dessa região são camadas sedimentares marinhas, aparentemente do período do Eoceno. Durante os tempos do Mioceno o litoral parecia estar parado várias centenas de pés acima do nível que se encontra no presente ... Esse período de erosão foi seguido por uma depressão, quando muitas das bacias foram formadas pelos vales que se encontravam perto da costa. Houve mudanças do nível do mar nesse período, mas elas não foram grandes, e as evidências indicam que esses movimentos não passaram de 30 a 40 pés. Enquanto isso, as fortes ondas do oceano e as correntes costeiras cortaram os sedimentos macios do Eoceno das penínsulas e as jogaram em ângulos com a costa. Esse processo continuou até que as entradas das baías fossem fechadas, ou quase completamente fechadas, e o litoral tornou-se quase reto ... Nós temos [assim] um litoral antigo, com longas, quase retas, praias de areia. As areias são ásperas e comumente misturadas com fragmentos de esqueletos calcários de animais e plantas que vivem na região. Na entrada de velhas enseadas as areais foram jogadas em direção à terra pelas ondas, que, em muitos lugares, pela fraca drenagem, foram parcial ou totalmente desligadas do mar pelos bancos de areia. E sobre lagos, piscinas ou correntes lentamente assim formados, plantas aquáticas e semiaquáticas vivem e morrem. A água doce é processada em ácido pela presença de grande quantidade de dióxido de carbono produzido pela decomposição orgânica. A água ácida do lado da terra, filtrada através dos bancos de areia na maré baixa, ataca a matéria calcária na areia e passa em direção ao mar, formando com ele uma solução, mas como ela entra em contato com o carbonato de cal em solução ele se deposita entre os grãos de areia. No momento em que os interstícios são completamente cheios, o banco de areia é endurecido, solidificando-se de forma que a água não pode passar por ele (Branner, jan. 1905, p.5, 8).

A postura interpretativa de Branner no final do século XIX sobre a formação geológica dos recifes de arenito e dos recifes de corais do litoral brasileiro era de pleno convencimento de que esta formação não se originava de formações vulcânicas ou outros fenômenos eruptivos, muito menos da deposição de materiais por ação de glaciais. Para ele, não haveria evidências que sustentassem esse tipo de explicação para os recifes de corais no Brasil. A particular formação, que remontava ao Cretáceo, era confirmada pela presença de uma fauna semelhante à zoologia do Caribe, e as pedras ferrosas e dolomitas atestavam os dinâmicos processos pelos quais passaram ao longo das idades geológicas esse tipo de formação. A compreensão geológicohistórica do litoral possibilitou a Branner (jan. 1905, p.11) interpretar o meio natural de uma forma dinâmica: "Na costa do Brasil os recifes são formados sob uma notável combinação da terra sob o mar, ilustração de um agradável e belo equilíbrio das forças da natureza".

\section{The Stanford Expedition to Brazil, 1911}

Em 1911, John Casper Branner organizou outra expedição ao Brasil, dessa feita para explorar mais de perto uma problemática darwinista: as causas da evolução a partir da 
divergência de caracteres das espécies separadas por barreiras naturais. O ambiente de críticas aos paradigmas darwinistas pelos defensores das interpretações alternativas à seleção natural foi mais uma vez o quadro teórico que sustentou as problemáticas da pesquisa de campo. A Stanford Expedition to Brazil (1911) se enquadrava na orientação teórica e metodológica darwinista vivida pelos cientistas de Stanford diante da divulgação das teorias alternativas da seleção natural. Branner e seu grupo pretendiam contribuir diretamente para o acúmulo de evidências da teoria da seleção natural e, assim, fazer a defesa do darwinismo diante das alternativas teóricas da mutação, ou evolução a largos passos das espécies.

A expedição foi coordenada por John Casper Branner e teve como membros Edwin Chapin Starks (1867-?), ictiologista, Harold Heath (1868-1951), fisiologista, ambos professores de Stanford, e Fred Baker (1854-1938), malacologista membro da San Diego Society of Natural History. Quatro estudantes foram convidados para auxiliar os trabalhos da expedição: Olaf Pitt Jenkins (1889-1983), George Casper Branner (1890-1969) e Earl Lieb (datas desconhecidas), estudantes de geologia, e William Mann (1886-1960), estudante de zoologia. O grupo partiu de Nova York em abril de 1911, visitou o Museu Paraense em Belém, onde foram recebidos e trocaram informações com Emilia Snethlage (1868-1929), fizeram coleta de espécies no litoral e sertões do Ceará e Rio Grande do Norte. Parte do grupo também realizou prospecções biológicas ao longo do rio Madeira, tendo passado alguns meses nas instalações da Estrada de Ferro Madeira-Mamoré. Branner ainda visitou a região da Chapada Diamantina, no interior da Bahia, e visitou amigos no Rio de Janeiro.

O roteiro proposto para a viagem era o litoral do Brasil entre o Amapá e o Rio Grande do Norte. A expedição pretendia explorar o litoral a partir de Natal até a região do rio Oiapoque, fronteira com a Guiana Francesa. Branner planejou o roteiro da expedição para que ela cumprisse seus objetivos científicos. Ele queria encontrar uma região bem delimitada do ponto de vista de sua reflexão sobre as causas das variações das espécies. Procurou demarcar um espaço que tivesse condições físicas e climáticas homogêneas para a vida marinha. Seu objetivo era constituir coleções zoológicas para observar a possível variação das espécies afetadas por uma barreira natural. Em carta ao geólogo Henry Shaler Williams (1847-1916), professor da Universidade de Cornell, detalhou com precisão sua intenção:

A ideia do grupo é ir para Natal, próximo ao cabo de São Roque, em abril, e com barcos que possam ao mesmo tempo entrar em baías rasas e estuários, coletar a fauna marinha de águas rasas desde Natal, norte do Cabo de São Roque em direção ao oeste, na foz do Amazonas, e então ao longo da costa até a Guiana Francesa. Por água rasa eu entendo tudo o que eu possa encontrar nos recifes de corais (Branner, 11 jul. 1910).

Ele tinha clareza do que queria focar com a montagem das coleções: a variação da vida marinha. Assim, procurou delimitar uma área com condições climáticas semelhantes, "praticamente uniformes", para fazer as observações de campo. Também do ponto de vista das correntes marítimas a área oferecia uma situação homogênea: toda a região sofre a ação da mesma corrente que se desloca na direção leste-oeste a partir do cabo de São Roque até o Amapá e daí ao Caribe. Além disso, praticamente toda a costa está situada a poucos graus norte e sul da linha do Equador, quase sempre se estendendo na mesma latitude. Entretanto, por mais que as condições fossem bem delimitadas do ponto de vista da sua localização, 


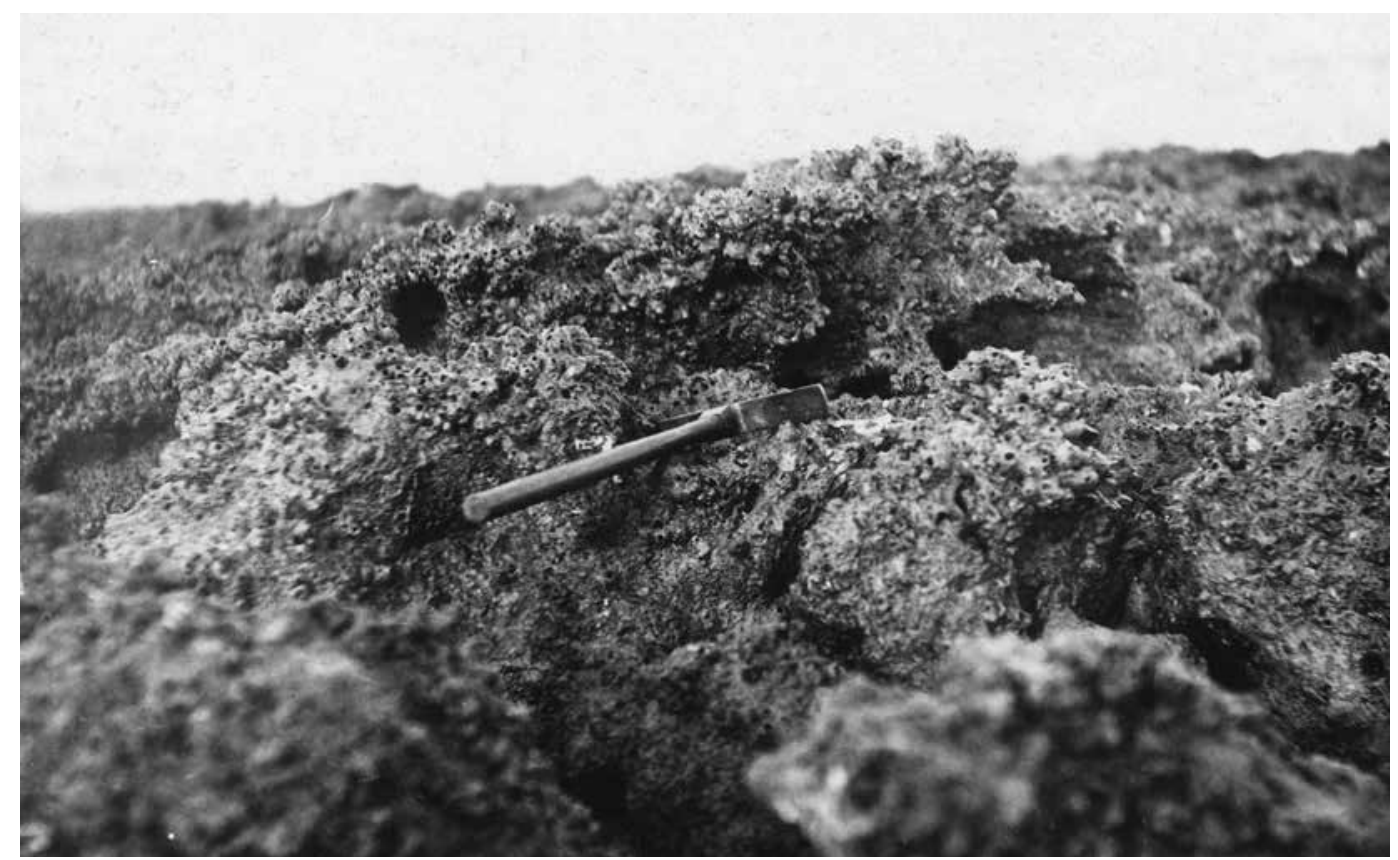

Figura 3: Pirangi, detalhe de estrutura do recife de coral (Branner-Agassiz expedition to Brazil, 1899; cortesia de Department of Special Collections/Stanford University Libraries)

a região sofre uma grande e importante interferência na foz do rio Amazonas: a enorme quantidade de água doce despejada no oceano. Esse era um fator importante na construção da problemática evolutiva de Branner: "Eu quero saber exatamente o que a barreira de água doce faz com a vida marinha". E continua: "Eu sei que ela [a vida marinha] é profundamente afetada, mas ninguém nunca fez esse estudo, e eu sei que não há melhor lugar para fazê-lo tão promissoramente". Ainda na carta a Henry Williams, Branner comenta a sua percepção da formação geológica da foz do Amazonas: "O transbordamento (flood) do Amazonas é uma coisa recente geologicamente, e como consequência não influencia muito longe. Eu antecipo isso a partir de estudos que lançam luz sobre as faunas do Cretáceo e do Terciário da região do golfo da América do Norte" (Branner, 11 jul. 1910).

Desde 1909, Branner alimentava a ideia de fazer uma expedição para explorar a costa ao norte de Natal, o que não foi possível em sua viagem de 1899. Em agosto de 1909, começou a planejar a expedição ao Brasil durante os meses de maio a agosto de 1910. Entretanto, as mortes de Joaquim Nabuco (1849-1910) e Alexander Agassiz o impediram de realizar a viagem. Nabuco, embaixador do Brasil nos EUA, estava ajudando Branner a selecionar contatos com os governantes brasileiros, e Agassiz iria contribuir financeiramente com a expedição. ${ }^{7}$

Do ponto de vista teórico, a expedição tinha como objetivo o estudo de uma área biogeográfica (o litoral da costa Leste-Oeste do Brasil), com condições físicas e climáticas bem definidas e que poderiam ser documentadas pela perspectiva das províncias zoológicas: a problemática central era se a foz do rio Amazonas representava ou não uma barreira biológica. Queriam saber se havia o isolamento geográfico da fauna marinha provocado 
pela grande quantidade de água doce lançada no oceano pelo rio. Em seu tempo geológico, teria a foz do rio interrompido o ritmo de trocas reprodutivas das espécies, dividindo a área em duas províncias zoológicas? A biogeografia do litoral foi assim investigada com uma problemática evolutiva. Visavam, dessa forma, mostrar que o ambiente de adaptação, variação sob isolamento, poderia produzir a evolução das espécies por seleção natural, validando a teoria da evolução de Charles Darwin.

Branner, como geólogo, estava preocupado com o tempo geológico necessário para que a evolução se processasse (e este foi um longo debate nos estudos evolutivos no decorrer dos séculos XIX e XX). Desde as grandes discussões da filosofia natural do século XVIII, passando pelo debate entre huttonianos e wernerianos no início do século XIX, às próprias discordâncias entre geólogos sobre a idade da crosta terrestre, além, é claro, do debate entre evolucionistas e criacionistas do qual Branner foi tributário, a noção de "tempo geológico" era fundamental para a validação da teoria evolutiva. A questão do tempo geológico da formação da foz do Amazonas tinha uma longa referência na literatura evolutiva desde que os naturalistas de meados do século XIX fizeram as primeiras interpretações da formação da bacia hidrográfica do Amazonas - especialmente Agassiz, mas também Wallace, Henry Walter Bates (1825-1892) e Richard Spruce (1817-1893).

Branner tinha a exata dimensão desse problema, sobre o qual propunha "lançar luzes". Os estudos de ictiologistas colocavam a área do litoral da costa Leste-Oeste do Brasil dentro da mesma biogeografia do Caribe. Não haveria distinção no aspecto das espécies da vida marinha dessas áreas. Tal constatação indicaria que a foz do Amazonas teria uma formação geológica relativamente recente e, por essa razão, não separaria a vida marinha a ponto de a especiação produzir novas espécies. A fauna marinha do Caribe era do Terciário; teria a mesma fauna se diferenciado na costa a partir da barreira geológica do rio Amazonas? Caso as pesquisas zoológicas realizadas pela expedição indicassem variações e adaptações evolutivas significativas se comparadas às espécies encontradas no Caribe, a ideia do "tempo necessário" para a que a evolução se processasse poderia ser afirmada, no mínimo problematizada, pelos defensores do darwinismo.

Entre 1911 e 1913, mais de duas dezenas de artigos foram publicadas como resultados dessa expedição, e versavam sobre temas como: morfologia, fisiologia, adaptação, mutualismo e descrições taxonômicas de novas espécies, gêneros e subgêneros de peixes, moluscos, insetos e abelhas, além de mapas e estudos geológicos (Branner, 1914). As coleções entomológicas, ictiológicas e malacológicas realizadas por Fred Baker e William Mann foram as que deram mais resultados do ponto de vista das publicações científicas.

A estratégia seguida foi a de montar pequenas coleções, mas de grande qualidade no que se refere à conservação das amostras e da seleção de espécies desconhecidas e ainda não classificadas. Uma vez nos EUA, essas coleções circularam entre diferentes pesquisadores e foram trabalhadas em diferentes instituições. Em Stanford, foram catalogadas e ficaram depositadas no museu de zoologia e na Hopkins Marine Station. As amostras das coleções de Mann e Baker circularam em diferentes instituições científicas, tais como: Field Museum of Natural History (Chicago), Bureau of Entomology (Washington), Museum of Comparative Zoology (Cambridge), Museum of the Brooklyn Institute (Nova York), California Academy of Sciences (São Francisco), entre outras. 
A identificação e a classificação das espécies de vida marinha foram feitas para dois distritos biológicos: o litoral entre Natal e o Maranhão, e a foz do rio Amazonas. Os moluscos representam 43 gêneros, 93 espécies e vinte subespécies - 33 espécies e 12 subespécies foram descritas como novas. Os peixes representam 96 espécies, 16 das quais descritas como novas. Atualmente, essas coleções se encontram em diferentes instituições nos EUA.

\section{Considerações finais}

Este artigo procurou delinear os contornos de uma extensa atividade de pesquisa científica de John Casper Branner no litoral do Brasil. As pesquisas sobre a biodiversidade que atuam na conservação biológica do planeta ainda carecem de um conhecimento anterior (histórico) sobre as áreas estudadas do ponto de vista dos ecossistemas atuais. A forma de reprodução das espécies, a morfologia, a fisiologia e a relação com o ambiente foram escrutinadas no início do século XX pelas expedições científicas, que, além de designarem as novas espécies, também constituíram coleções preciosas e raras, hoje dispersas em diferentes instituições dos EUA e do mundo. Reunir, portanto, esse referente empírico (que é uma árdua tarefa para o historiador da ciência) pode não só valorizar em termos históricos o conhecimento produzido no intercâmbio entre cientistas, mas contribuir de modo direto para o conhecimento das alterações biológicas pelas quais historicamente essas espécies passaram e ainda passam.

Pensar uma história biológica das espécies do ponto de vista de uma história da ciência visa a objetivos que não se restringem apenas ao aspecto documental de uma investigação histórica, pode contribuir diretamente para o conhecimento das alterações biológicas por que essas espécies passaram sob a ação de diferentes agentes (climáticos, físicos e da própria intervenção humana). Esse pode ser um diferencial para os estudos de conservação biológica. O estudo das coleções biológicas construídas ao longo da experiência científica de John Branner no Brasil e das condições de produção científica do início do século passado busca não só uma contextualização, mas a qualificação dos contornos do objeto observado na prática cotidiana do fazer científico.

Em 1919, dois anos antes de sua morte, John Casper Branner publicou o "Mapa da geologia do Brasil" em Washington, na Geological Society of America. Acompanhado de uma análise da evolução geológica do Brasil e de uma bibliografia de estudos e descrições geológicas para cada estado brasileiro, Branner realizava o seu maior propósito, que o acompanhou desde sua formação científica, vida profissional como pesquisador e como professor: o desenvolvimento dos estudos geológicos e a divulgação da geologia brasileira nos meios acadêmicos norteamericanos.

\section{AGRADECIMENTO}

Esta pesquisa contou com o apoio financeiro da Capes e foi desenvolvida no Center for Latin American Studies (Stanford University). 


\section{NOTAS}

${ }^{1}$ Branner foi assistente de Charles Frederick Hartt na Comissão Geológica do Império (1876), quando viajou pela primeira vez pelo litoral entre o Rio Grande do Norte e a Bahia.

${ }^{2}$ Largent atenta para o fato de que os historiadores da biologia geralmente olharam a produção científica do período entre 1880 e 1930 com o filtro da síntese moderna do darwinismo: "A noção de um eclipse de Darwin ou o eclipse do darwinismo é seriamente problemática. A ideia é inapropriadamente determinista. Ela obscurece o trabalho realizado por duas gerações de biólogos investigadores. É uma metáfora que implica uma idade obscura do pensamento evolutivo, e serve como base para a produção de uma história descontínua do pensamento evolutivo" (Largent, 2009, p.15). O autor sugere o termo "interfase" para tratar o período, e também recomenda um olhar mais detido de interpretação histórica para entender esse produtivo e vital momento da biologia evolutiva.

${ }^{3}$ De uma forma geral, registravam os avanços tecnológicos que permitiam a análise dos processos mecânicos da divisão celular (Weissman, Haldane, Boveri, Mc Farland, Romanes etc.), entusiasmavam-se com os estudos experimentais, os métodos estatísticos e o uso dos parâmetros físico-químicos para a comprovação da hereditariedade. Por outro lado, rejeitavam a ideia de que a evolução era intrínseca aos organismos (ortogênese) e que a evolução poderia se dar a largos passos (mutação). Desenvolveram a ideia de que uma sistemática taxonômica poderia ser feita com base nos estudos da morfologia das espécies coletadas em campo, com especificações bionômicas: espécies individuais compreendidas dentro das fronteiras geográficas da distribuição da vida animal no globo, barreiras geográficas, além de adaptações e variações ao ambiente.

${ }^{4}$ Para uma análise do vigor na defesa do darwinismo de Kellogg e da pertinente identificação do debate evolutivo no início do século XX, vale registrar a seguinte afirmação de Gould (2002, p.164): "Eu estava particularmente feliz por saber que as categorias de Kellogg, diferentemente nomeadas e analisadas, eram idênticas às que temos reconhecido aqui. Ele divide a multiplicidade de propostas em discussão no seu tempo entre as que 'auxiliam a' e as que eram 'alternativas à' seleção natural. Entre as auxiliares, que ajudam, expandem, melhoram ou se encontram dentro do espírito do darwinismo, Kellogg destaca dois temas principais: os estudos de Wagner, de Jordan, e Gullick sobre o papel do isolamento na formação das espécies; e os modelos hierárquicos de seleção promovidos por Roux e Weissman. Observei com especial satisfação que Kellogg reconheceu hierarquia como auxiliar, e não uma refutação ao darwinismo, o mesmo debate que define o tema principal deste livro".

${ }^{5}$ Alexander Agassiz, filho de Louis Agassiz e estudioso da biogeografia dos recifes de corais.

${ }^{6}$ No campo zoológico foram publicados três artigos com descrições taxonômicas de peixes, crustáceos e moluscos. Mary Jane Rathbun (1860-1943), curadora da seção de crustáceos do Smithsonian Institution desde 1884, realizou o inventário dos crustáceos; Harriet Richardson (1874-1958) classificou uma nova espécie de crustáceo; Charles H. Gilbert (1859-1928) organizou a coleção de peixes. As coleções foram montadas a partir de coletas nos recifes de corais que cobrem os recifes de arenito entre o cabo de São Roque, no Rio Grande do Norte, e o Estado das Alagoas. Arthur W. Greeley (1875-1904), estudante de zoologia em Stanford, foi o naturalista responsável pela coleta. A coleção de crustáceos (71 descritas e sete novas espécies identificadas) foi doada ao United States National Museum. A coleção dos peixes, organizada em 85 espécies (quatro delas classificadas como novas, e um gênero definido como novo), foi depositada no museu de história natural em Stanford (Branner, ago. 1900).

${ }^{7}$ Um estudo detalhado da correspondência de Branner no período entre 1909 e 1911 nos mostra a rede de contatos com intelectuais e cientistas no Brasil que viabilizaram sua expedição, enviando informações sobre os meios de transporte, mapas detalhados e informações sobre as conjunturas políticas do país. Dentre os seus colaboradores mais frequentes no Brasil, destacam-se: Orville A. Derby, Alfredo de Carvalho (1870-1916), Miguel Arrojado Ribeiro Lisboa e João Capistrano de Abreu (1872-1921). Branner discutia com Arrojado Lisboa os serviços geológicos necessários ao sucesso da implementação da Inspetoria de Obras contra as Secas (1909). Com outros colaboradores, como Theodoro Sampaio, discutia questões como o ensino da língua portuguesa nos EUA e temas de política internacional. Em carta a Orville A. Derby, Branner (18 de nov. 1909) reafirma o seu plano de viagem ao Brasil para o estudo da vida marinha dos recifes do litoral da costa Leste-Oeste: "Nesse sentido, espero fazer um trabalho de primeira classe, e, por meio da coleta da fauna marinha, obter um ponto de partida com um trabalho completamente paleontológico. Um dos problemas que gostaria especialmente de obter luz sobre ele é a influência sobre a migração marinha do grande volume de água doce que o Amazonas derrama no Oceano Atlântico desde os antigos tempos geológicos. Nós já sabemos que existe uma influência na fauna marinha da região das Índias Ocidentais, mas a questão permanece no que diz respeito às relações com aquelas faunas para do Norte do Brasil". 


\section{REFERÊNCIAS}

ALLEN, Garland. Life sciences in the Twentieth Century. History of sciences series. New York: John Wiley \& Sons. 1978.

BOWLER, Peter.

Evolution: a history of an idea. Berkeley/London: University of California Press. 1983.

BRANNER, John Casper.

The papers of Stanford Expedition to Brazil, 1911.

Palo Alto: Stanford University. 1914.

BRANNER, John Casper.

Carta a Henry S. Williams. Palo Alto. Special Collections and University Archives, John Casper Branner Papers; SC 0034, Box 8, Folder 28 (Cecil Green Library, Stanford University). 11 jul. 1910.

BRANNER, John Casper.

Carta a Orville Derby. Palo Alto. Special

Collections and University Archives, John Casper Branner Papers; SC 0034, Box 8, Folder 28 (Cecil Green Library, Stanford University). 18 nov. 1909.

BRANNER, John Casper.

Stone reefs on Northeast coast of Brazil. Bulletin of the Geological Society of America, v.16, p.1-12. jan. 1905.

BRANNER, John Casper.

The stone reefs of Brazil, their geological and geographical relations, with a chapter on coral reefs. Bulletin of The Museum of Comparative Zoology, v.44, p.1-285, 99 plates. maio 1904.

BRANNER, John Casper.

Results of Branner-Agassiz Expedition to Brazil. Two Characteristic Geologic Sections on the Northeast Coast of Brazil. Proceedings of the Washington Academy of Sciences, v.2, p.185-201. ago. 1900.

BRANNER, John Casper.

The stone reef at the mouth of Rio Grande do Norte. The American Geologist, v.24, p.342-344, 2 fig. dez. 1899.

BRANNER, John Casper.

A suposta glaciação do Brasil. Revista Brasileira, ano 2, t.6, p.106-113. 1896.

BRICE, William B; FIGUEIRÔA, Silvia F. de M. Charles Hartt, Louis Agassiz, and the controversy over Pleistocene glaciations in Brazil. History of Science, v.39, part 2, n.124, p.61-184. jun. 2001.

COLEMAN, William.

Biology in the Nineteenth century: problems of form, functions and transformation. Cambridge: Cambridge University Press. 1985.
GOULD, Stephan Jay.

The structure of evolutionary theory. Cambridge: Harvard University Press. 2002.

GREENE, Mott T.

Geology in the Nineteenth century: changing views of changing world. Ithaca: Cornell University Press. 1982.

HARTT, Charles Frederick.

Thayer Expedition: scientific results of a journey in Brazil by Louis and his travelling companions. Geology and physical geography of Brazil. Boston: Fiels, Osgood \& Co. 1870.

JORDAN, David Starr.

The days of a man: being memories of a naturalist, teacher and minor prophet of democracy. New York: World Book Company. 1922.

JORDAN, David Starr.

The origin of species through isolation. Science, v.22, n.566, p.546-562. nov. 1905.

KELLOGG, Vernon Lyman.

Darwinism To-day: a discussion of present-day scientific criticism of the darwinian selection theories, together with a brief account of the principal other proposed auxiliary and alternative theories of species-forming. New York: Henry Holt Co. 1907.

KLAVER, Jam M.T.

Geology and religious sentiment: the effect of geological discoveries on England society and literature between 1829 and 1859 . Leiden: Brill. 1997.

KUHN, Thomas.

A estrutura das revoluções científicas. São Paulo: Perspectiva. 2011.

LARGENT, Mark A.

The so-called eclipse of darwinism: insights into the history of evolutionary studies, 19001970. In: Cain, Joe; Ruse, Michael (Org.). Descended from Darwin. Philadelphia: American Philosophical Society. p.3-21. 2009.

MAGNUS, David.

In defense of natural history: David Starr Jordan and the role of isolation in evolution. Tese (Ph.D.) Department of Philosophy, Stanford University, Palo Alto. 1993.

MAYR, Ernest.

The growth of biological thought: diversity, evolution and inheritance. Cambridge/London: The Belknap Press of Harvard University Press. 1982. 
ORESKES, Naomi.

The rejection of continental drift: theory and method in american earth sciences. New York: Oxford University Press. 1999.

ROBERTS, Jon.

Louis Agassiz: poligienismo, transmutação e metodologia científica: uma reavaliação. In: Domingues, Heloisa Bertol et al. (Org.). Darwinismo, meio ambiente e sociedade. São Paulo: Via Lettera; Rio de Janeiro: Mast. p.73-99. 2009.

SANTOS, Ademir Pereira dos.

Theodoro Sampaio: nos sertões e nas cidades. Rio de Janeiro: Versal. 2010.
SOUZA, Gastão Galvão de Carvalho.

As conferências de Agassiz após seu retorno da Amazônia (maio de 1866). In: Domingues, Heloisa Bertol et al. (Org.). Darwinismo, meio ambiente e sociedade. São Paulo: Via Lettera; Rio de Janeiro: Mast. p.101-112. 2009.

WOURMS, Pohn.

The relations between comparative embryology, morphology, and systematics: an American perspective. In: Laubichler, Manfred D.; Mainschein, Jane. From Embryology to Evo-Devo: a history of developmental evolution. Cambridge, MA; London: The MIT Press. p.215-266. 2007. 